\title{
IDENTITY, IDENTITY FORMATION AND IDENTITY WORK IN ENTREPRENEURSHIP: CONCEPTUAL DEVELOPMENTS AND EMPIRICAL APPLICATIONS
}

\author{
Claire M Leitch \\ Professor of Entrepreneurial Leadership \\ Department of Leadership and Management \\ Lancaster University Management School \\ Lancaster University \\ Bailrigg \\ Lancaster \\ England \\ LA1 4YX \\ UK
}

\author{
Richard T Harrison \\ Professor of Entrepreneurship and Innovation \\ Centre for Strategic Leadership and Centre for Entrepreneurship Research \\ University of Edinburgh Business School \\ 29 Buccleuch Place \\ Edinburgh \\ Scotland \\ EH8 9JS \\ UK
}




\title{
IDENTITY, IDENTITY FORMATION AND IDENTITY WORK IN ENTREPRENEURSHIP: CONCEPTUAL DEVELOPMENTS AND EMPIRICAL APPLICATIONS
}

\author{
Claire M Leitch and Richard T Harrison
}

\begin{abstract}
This paper reviews the current status of research into entrepreneurial identity. Identities - individual and organisational - can potentially serve as powerful elements that both drive and are shaped by entrepreneurial actions. Identity is, of course, a complex construct with multidisciplinary roots and consequentially a range of conceptual meanings and theoretical roles associated with it. Building on a framework for identifying schools of thought in the social sciences, we highlight the need for more critical studies of entrepreneurial identity that recognise, first, that entrepreneurial identity is a dynamic and fluid rather than (relatively) fixed and unchanging feature, and second, that research attention should shift from the analysis of identity per se (the identity-as-entity position) to the identity work processes through which entrepreneurial identities are shaped and formed (the identity-asprocess position). Following a summary of the key contributions of the five papers included in this Special Issue we conclude with some pointers for future research.
\end{abstract}

Key words: entrepreneurial identity; individual identity; social identity; organisational identity; identity work; process 


\title{
IDENTITY, IDENTITY FORMATION AND IDENTITY WORK IN ENTREPRENEURSHIP: CONCEPTUAL DEVELOPMENTS AND EMPIRICAL APPLICATIONS
}

\begin{abstract}
Introduction
Even though the construct of identity has gained common currency in contemporary social science it is only relatively recently that it has come to the attention of scholars working in entrepreneurship: "knowledge of the role of founder identity in entrepreneurial processes and outcomes is in its very early stages" (Fauchart and Gruber, 2011: 954; Navis and Glynn, 2011). In the entrepreneurial domain it is recognised that the actions and behaviours of a founder or founding team on the creation and subsequent development of a firm are profound. This is because entrepreneurial activities are infused with meaning as a result of the expression of an individual's identity. As a number of commentators have suggested, identities are the primary sources of motivation for human behavior. Along with entrepreneurial roles, which "are a set of socially held behavioural expectations attached to the positions external to an individual” (Murnieks and Mosakowski, 2007: 2) identities can potentially serve as powerful elements that drive entrepreneurial actions.
\end{abstract}

In entrepreneurship as in other domains, identity is a complex construct, which as a result of its multi-disciplinary roots, has a range of conceptual meanings and theoretical roles associated with it. It can be viewed as our representation of the internalization and incorporation of socially-held behavioral expectations. As such, it can have an important impact not only on the way we feel, think and behave (present) but also on what we aim to achieve (future). Further, identity provides us with a frame of reference with which to interpret social situations and potential behaviours and actions in all domains, as it appears to signify who we are in relation to, and how we differ from, others.

Falck et al (2009) suggest that an individual's sense of identity is influenced by considerations of social desirability. As entrepreneurs do not construct their identities alone, identity can be regarded as a fundamental bridging concept between the individual and the social (Ybema et al, 2009; Watson, 2009). Essentially, it creates a medium through which the entrepreneurial self and the social interact, as the norms and prescriptions, which arise from social interaction impact upon individual behavior (Laakkonen, 2012). As firm creation is both an individual or team and an inherently social activity, and organisations are social constructions, there is value for entrepreneurship scholars in using the bridging construct of identity. This can be applied to exploring and explaining entrepreneurs' attempts to understand who they are and are not and what they do and do not, in addition to what they should and should not do at all stages in the entrepreneurial process, from entrepreneurial intention through the creation and development of new ventures to the process of entrepreneurial exit.

Beyond this, there is an opportunity to consider the relationship between identity at the level of the individual entrepreneur, within the entrepreneurial team and at the level of the organisation. If organisational identity is what is central, distinctive and 
enduring about an organisation (Albert and Whetten, 1985) then it serves as a cognitive frame for understanding reality, as a sense-making discourse about and within it as well as a set of shared assumptions and collective claims about it. Organisational identity is embedded in organisational culture and expresses cultural understandings through symbols and images (Hatch and Schultz, 2002). As Gioia et al (2013) have noted there is a major debate between the view that identity is stable over time (the enduring identity proposition) and that sees it as more changeable (the dynamic identity proposition). For entrepreneurship scholars, and in particular for those concerned with the processes of organisational emergence and development, the interaction between identity formation and change in the entrepreneur and identity formation and change in their organisation becomes an important, but hitherto relatively unexplored, research avenue.

In seeking to build on this research, this special issue can be seen as a response to earlier calls for more attention to be paid to "how individuals construct their social world to entrepreneurial behavior" (Reynolds, 1991: 67), on the basis that "the social formation of the entrepreneurial self is still an underdeveloped topic of research" (Down and Reveley, 2004: 236). There is scope to more fully enrich our theoretical understanding of identity and identity formation, at both individual and organizational levels, and its relationship to entrepreneurial processes, practices and activities in two ways.

First, entrepreneurial identity is a dynamic and fluid rather than a (relatively) fixed and unchanging feature, shaped by different life episodes and the patterns of those (Lindgren and Wåhlin, 2001). It is, in this view, a complex, increasingly fluid, multilevel and multi-dimensional construct comprising multiple sub-identities rather than a univocal (and unchanging) self, and as such has a profound effect not only on the way we feel, think and behave but also on what we aim to achieve (Sen, 2006; van Knippenberg et al, 2004). Accordingly, it is vital that its dynamics are better understood, particularly in determining how actors behave in an entrepreneurial context.

Second, attention is shifting from the analysis of identity per se to the process through which entrepreneurial identities are formed and shaped - only by understanding the dynamics of identity formation through identity work (Watson, 2009) is it possible to relate identity to entrepreneurial outcomes. While much of the research to date has focused on understanding identity, it is increasingly being recognised that insufficient attention has been paid to the process of identity formation (Gioia et al, 2013) and how this is related to the processes of organising, that is, "the routine activities which characterize much of organizational life" as well as "the objectives that organizations (at least notionally) pursue” (Coupland and Brown, 2012: 2).

\section{Discourses of Entrepreneurial Identity}

Much of the research on entrepreneurial identity has been empirical, employing a number of concepts (among them, role identity theory, social identity theory, structural identity theory, narrative and discourse analysis) to explore its role and impact. Scholars of entrepreneurial identity tend to comprehend the field and the nature of the phenomenon within the narrow bounds of their own research interests. 
Echoing Gartner (2010) this research sits within the discipline structure of entrepreneurship as a field of study, which like any management discipline can be seen as a "particular historical and social mode of engagement that restricts what is thinkable, knowable and doable in its disciplinary domain” (Johnson and Duberley, 2000: 101-102). However, these domains are not discrete and, as is common more generally, identity research in entrepreneurship is characterised by importing theories from other disciplines (Kenworthy and McMullan, 2012; Harrison and Leitch, 1996). The fact that theory in entrepreneurship is exogenous, in the sense of being derived from theories and constructs developed elsewhere, rather than endogenously developed within the field, poses a major challenge.

The interdisciplinary transfer of theories, concepts and constructs is very often incomplete in that it does not fully take into account their intellectual history, the current deliberations over their efficacy and developments in the evolution of thinking in the parent discipline. In other words, although valuable in enriching and providing a stimulus to the development of entrepreneurial identity research, the de facto reliance on a snap shot of debates elsewhere rather than substantive engagement in the ongoing conversation within them may limit the benefits we gain from this transfer (Pohl and Hirsch Hadron, 2008; Losee, 1995). This implies both risk and opportunity (Gartner, 2010). The risk is that researchers continue to draw on their preferred mix of research designs and theories while remaining unaware, even dismissive, of studies within other discourses. Consequently, the development of a deeper multi-faceted understanding of the phenomenon is constrained. The opportunity, however, is that engaging with different discourses can help highlight the taken-for-granted assumptions in entrepreneurial identity research, and thus open up new avenues of research, stimulate new questions and help generate new insights (cf. Mabey and Morrell, 2011).

For Davidsson (2013) the entrepreneurship field as a whole has been created to a significant extent by certain normative ideas, methods and approaches. Within this there is growing recognition that a European discourse of entrepreneurship can be differentiated (by degree, rather than in kind) from the dominant, North American one (Steyaert, 2007). This discourse is increasingly characterised by "a willingness to step outside of the entrepreneurship field, itself, to embrace a variety of ideas, particularly from philosophy and the humanities and... a concern for the 'other', so as to challenge the unspoken and often unrecognized 'taken-for-granted' aspects of what entrepreneurship is and what it might be” (Gartner, 2013: 6). In this Special Issue we have assembled a number of papers that demonstrate how traditions other than the normative one may be fruitfully employed to point new contexts for research within which new questions can be posed. This is achieved by stepping outside the narrow entrepreneurial research tradition to draw on wider contemporary debates in management and the social sciences that are relevant to the construction and analysis of entrepreneurial identity at individual and organisational levels. Thus, Gartner's concern for the 'other', moving beyond the often the-taken-for-granted nature of entrepreneurship research is demonstrated.

In focusing on the underlying discourses of research, that is, ways of thinking about research positions which highlights their assumptions and relationships, the framework developed by Alvesson and Deetz (2000) in their approach to critical 
social science research is useful. Following them we use two dimensions to classify the discourses of entrepreneurial identity research. First, 'consensus-dissensus seeking' focuses on the relation of research practices to dominant social discourses, contrasting perspectives on the basis of the extent to which they work within (consensus) or disrupt (dissensus) the dominant set of structurings of knowledge, social relations and identities. Second, 'local/emergent-elite/a priori' conceptions focus on the origin of concepts and problem statements as central to the process of undertaking research. Local/emergent conceptions are developed in relation with organisational members and transformed in the research process, while 'elite/a priori' conceptions, are those brought to the research by the researcher and generally held static throughout the research process. This distinguishes between concepts developed with the organizational members being studied and those applied to them (Alvesson and Deetz, 2000: 28) ${ }^{1}$. Taken together these define four 'prototypical discursive features' - normative, interpretive, critical and dialogic - which can be applied to locate exemplars of entrepreneurial identity research (Figure 1).

\section{Insert Figure 1 here}

The mainstream discourse on entrepreneurial identity has suffered from taken-forgranted assumptions about the role of consensus and the appropriate sourcing of explanatory concepts, set largely within a normative discourse which, we would argue, is predicated on an ontology of being. Drawing on Alvesson and Deetz' (2000) analytical framework we argue that these presumptions in mainstream entrepreneurial identity discourse have silenced important and related discourses that occur in the research traditions from which identity theory draws. By identifying and giving voice to these discourses, research on entrepreneurial identity will be enriched by problematizing prior problems and claims in addition to the generation of a rich new set of research questions and approaches that suggest greater centrality to the process of identity creation than prior research has claimed or supported. In this, we emphasise the importance of developing research that adopts a local/ emergent perspective. While there is an extensive, largely European, interpretivist literature on entrepreneurial identity, this is mainly focused on the analysis of socially constructed identities-as-entities and of the process-as-entity of their development and change.

Within the normative discourse, concepts are considered to be broadly self-evident, their qualities are objectively defined and essentialist and expressed as pre-determined traits, styles or personality. As such, identity is viewed as an external representation and the analytical frameworks employed concentrate on establishing the co-variance between it and other phenomena of entrepreneurial interest. This research is grounded in the principles and practices of modernity, in which attempts are made to investigate, measure, analyse, record and classify particular phenomena. In the interpretive discourse identity is considered to be socially and culturally construed, recognising that identity is a social as well as a personal construct. However, while this work has been insightful there is an underlying assumption, as with the normative discourse, that identity itself is an unproblematic construct. Identity research in entrepreneurship, whether in the normative or interpretive discourse, has tended to

\footnotetext{
${ }^{1}$ This broadly parallels the cultural anthropologist's distinction between emic research, which investigates how local people think, how they perceive and categorize the world, what has meaning and how they explain things, from the etic (or scientist-oriented) approach which shifts the focus from local observations, categories, explanations and interpretations to those of the researcher (Harris, 1976; Morris, Leung, Ames and Lickel, 1999).
} 
focus on either social identity theory (self-identification with some group or social category) or (role) identity theory (Powell and Baker, 2014), with growing recognition of the 'looking-glass' relation between self-identity and a variety of social identities (Watson, 2009; Anderson and Warren, 2011). The further development of entrepreneurial identity research within the interpretive discourse will build on the explicit recognition that the key conceptions and understandings derive not from theory per se, but from the interaction with, and input from, the subjects under study. In this identity is viewed not as an objectively defined phenomenon but as a fluid consequence arising from, contributing to and being shaped by social practices (Mabey and Morrell, 2011: 110).

The critical discourse shares with the normative an emphasis on the objective existence of ultimate truths about the social world, but recognizes that identity as experienced by, and manifest in individuals and groups, such as entrepreneurs, is socially, politically and historically mediated via competing ideologies and power relations. Central to this discourse is an emphasis on emancipation from the unthinking acquiescence to, or adoption of, social dynamics, ideologies and identities. The dialogic discourse focuses on the constructed nature of people and reality, the fragmentation and potential disunity in any discourse and the subjectivity of identity as inherently fragile and temporary. In this, therefore, identity is continually in the process of construction and does not comprise a single static entity. Instead "group and personal identity cannot be seen as fixed or unitary... dialogic studies theorists hope to show the partiality (the incompletion and onesidedness) of reality and the hidden points of resistance and complexity” (Alvesson and Deetz, 2000: 36).

The implication of this analysis is not that these discourses are completely discrete and isolated, for they are by definition permeable and fluid. They do, however, embody distinctions in discourses that are important and lead to contrasting conceptions of what identity is. These in turn have significant implications for the framing of entrepreneurial identity research questions, for our understanding of what constitutes 'data', for our view of how these data are interpreted and for how our research findings may be used to inform practice. In essence, how we ask the questions, "what is entrepreneurial identity?", "how is it formed?", "How do we measure it?" and "how we develop it, change it or transform it?", will differ from discourse to discourse.

There is growing recognition in other domains that the use of multiple discourses is to be encouraged (Fairhurst, 2009). Most entrepreneurial identity research, including the papers in this Special Issue lies within the normative and interpretive discourses, where the emphasis is on patterning identity in the dominant, consensus-oriented social debate. Following Alvesson and Deetz (2000) we believe there is scope to situate this research within the dissensus discourse, where the emphasis in on the disruption of the dominant structuring of knowledge and social relations. Interpretivist research have begun to doubt the logic and efficacy of representing a consensual unified culture and have devoted more attention to uncovering its fragmentation, tensions and processes for managing conflict. This suggests that there is scope for a great rapprochement between the interpretive approach on the one hand and the critical and dialogic approaches on the other. Whilst studies grounded in these discourses share similar research philosophies (drawing on ethnography, 
hermeneutics and phenomenology to inform their qualitative method) they differ in terms of their underlying ontology.

Although the papers in this Special Issue still primarily adhere to an essentialist perspective of identity we believe there is a major opportunity for research which is grounded in a dialogic one highlighting the fragmentation of potential disunity inherent in any discourse. From this perspective insufficient attention has been paid in entrepreneurship to the process of identity construction and how this is related to the processes of organising, that is, "the routine activities which characterise much of organizational life" as well as "the objectives that organizations (at least notionally) pursue” (Coupland and Brown, 2012: 2). If identity is increasingly viewed as being friable, fluid, ephemeral and fragile (Bauman, 2000) then the research focus must shift from identity per se to the processes of identity formation (Ybema et al, 2009; Clegg and Baumeler, 2010; Coupland and Brown, 2012). Given that identity "is crucial to how and what one values, thinks, feels and does in all social domains, including organisations” (Albert, Ashforth and Dutton, 2000: 14), it is vital that it is better understood, particularly in determining "how actors insert themselves into organisational life" (Carroll and Levy, 2008: 76). On this basis, the papers in this Special Issue focus inter alia on the processes though which entrepreneurial identities are formed and shaped, and argue that only by understanding the dynamics of identity formation will it be possible to relate identity to entrepreneurial outcomes.

\section{Summaries of Papers}

Five papers comprise this Special Issue, three focusing on the creation of an entrepreneurial identity at the individual level and two at an organisational level. The three individual-level papers, explore the link between entrepreneurial identity and entrepreneurial actions and outcomes, which have not been fully explored in the literature to date (Lewis forthcoming; Yitshaki and Kropp, forthcoming; Alsos et al, forthcoming). Specifically the authors investigate the ways in which entrepreneurial identity relates to the entrepreneurial process and how that identity shapes an entrepreneur's behaviours. These were considered in the context of social entrepreneurship, high-technology and tourism drawing on studies conducted in New Zealand, Israel and Norway. The authors of the remaining two papers draw attention to the challenges faced in organisational identity development arising from the tension between demonstrating uniqueness from, at the same time as similarities (sameness) with, a peer group (Snihur forthcoming; Nelson et al, forthcoming). While Snihur's paper is empirical and Nelson et al's conceptual both ground their discussions in social constructivism and illuminate the importance of intra- and inter-organisational relationships and the individual-collective (organisational, group, national etc) interface.

The focus of Lewis's exploratory research is to understand how identities are built, not just how they are perceived. Specifically, she is interested in how the building blocks underpinning an identity are collected and arranged within a particular context. Lewis argues that the identity capital model devised by Côté (1996), in response to his concerns with the increasing demands on young actors to cope with identity transitions in late modernity, is particularly apt when the focus of study is identity work. Given that youth experience is at the core of the model it is especially germane to use when exploring identity work among the young. 
Accordingly, Lewis employs the model to explore how a young social entrepreneur, while at university, accumulated, deployed and exchanged his identity capital during the launch of his social venture. Côté's model is grounded in social psychological approaches and thus highlights the relationship between social context and identity formation. Identity capital resources cover a diverse range of tangible and intangible resource bases including educational, social and psychological. The accumulation of identity capital, acquired through an actor's identity exchanges with others captures the process of becoming as well as that of fitting in, in other words, establishing credibility.

Identity work is relatively unexplored in social entrepreneurship settings, which can be attributed to the relative immaturity of the topic or the belief that social entrepreneurship is simply a sub-set of entrepreneurship and that not worthy of attention in its own right. Nevertheless, given that discrepancies have been identified in the motivations, intentions and antecedent pathways between actors establishing profit and not-for-profit ventures (Germak and Robinson, 2014) it would seem to be reasonable to suggest that socio-cultural influences should not be ignored in identity work.

Lewis presents an interpretive, longitudinal, single case study of a social entrepreneur who in the wake of the earthquakes in Christchurch in 2010-2011 established an initiative bringing together student volunteers to provide services and care to those affected. She employed a number of primary and secondary data collection methods including interviews, field notes and reflections from the participant to obtain insights into his lived experiences, perceptions and sense-making about his identity capital asset accrual and deployment. In interpretive research context is vital and goes beyond merely capturing the characteristics of a place or space (Gill and Larson, 2014) but instead takes cognizance of the embeddedness of an actor within his/ her historic and contemporary environments and the impact these have on identity formation and enactment.

On the basis of her analysis Lewis found that historic identity capital investment and the resulting capital asset portfolio enabled effective leveraging for not only the entrepreneur's own identity embodiment but that of his organization and its membership. This emphasizes the role of synthesis in creating, sustaining and amplifying the dual-organisational aspects of identity as well as the symbiotic relationship between a founder's identity and that of his venture.

Yitshaki and Kropp examine entrepreneurial passion and components of entrepreneurial identity in two different contexts with different dynamics and goals high-tech entrepreneurship and social entrepreneurship. They argue that passion and identity, which motivate entrepreneurs to identify opportunities and establish new ventures, are interlinked. They view the relation as a feedback loop where microidentities and passion reinforce each other and which vary across different categories of entrepreneur creating a different dynamic. In particular, passion nourishes identity construction, thus passion and identity are self-reinforcing and synergistic.

Unlike previous research, which has examined how entrepreneurs recognize and act on their social identity which they derive from their knowledge and understanding about their membership of a social group, Yitshaki and Kroop focus instead on how 
they manage their self-concept within their role identity. In other words, how do entrepreneurs create, support and sustain their micro-identities in the context of how they conceptualise and understand the entrepreneurial role, which comprises many, frequently conflicting elements. Internalisation of the meanings associated with this role will influence an actor's recognition and pursuit of entrepreneurial opportunities.

Yitshaki and Kroop use a narrative approach, drawing on the life stories of high-tech and social entrepreneurs in Israel to explore the relationship between passion and identity. The life-story method permits understanding of how individuals express their self-identity. This is achieved through the ways in which they make sense and reference their historical, contemporary and future perceptions and actions to construct and articulate their entrepreneurial micro-identities. Such an approach does not seek to establish accurate scientific truth but instead acknowledges that a narrative truth is presented comprising remembered facts and a presentation of an individual's selves according to specific momentary influences. They adopt a grounded theory approach to data analysis with particular attention made to passion, becoming an entrepreneur, ways in which participants felt different (otherness) or similar (sameness) to others as well as claims of 'who we are' or 'what we do' representing homogeneity and heterogeneity.

Their findings reveal that entrepreneurs operating in the very different contexts of high-tech and social entrepreneurship attribute different meanings for their passion. Further, based on self-perceptions of otherness and sameness entrepreneurial identities differed across these contexts. While high-tech entrepreneurs' passion was linked to opportunity recognition and exploitation social entrepreneurs focused on the creation of social value and emotional payback. The source of self-identity for social entrepreneurs was based on life events and appears to be constructed before engaging in entrepreneurial activity. On the other hand, for high-tech entrepreneurs both past and ongoing personal, occupational and entrepreneurial experiences were salient for the creation of their self-identity.

Like Yitshaki and Kroop, Alsos et al take a predominately essentialist view of identity, assuming that it is stable and fixed, in a state of 'being', but acknowledge the relevance of processual one where the focus is on 'becoming' and identity is considered to be emergent and in a continual state of flux. Drawing on Fauchart and Gruber's (2011) typology of entrepreneurial identities, Darwinians, Communitarians and Missionaries they examine the relationship between entrepreneurial identity and the extent to which entrepreneurs, depending on their perception of uncertainty and expertise, adopt effectual and causal behaviours (Sarasvathy, 2001) in the start-up phase of new ventures. They argue that while researchers indicate that identity has consequences for entrepreneurial behaviour there has been limited research into this, particularly into how variations in different entrepreneurial identities may lead to different types of behaviour.

Alsos et al adopt a two stage, mixed methods approach permitting them to generate and test theory. In stage one, to assist with hypothesis development between entrepreneurial identity and effectual and causal behaviour exploratory interviews were conducted with entrepreneurs of experience-based start-ups in the tourist industry. In stage two, the hypothesis generated at the end of stage one were tested by administering a questionnaire to Norwegian start-up firms. The findings from their 
research confirm that entrepreneurial identity influences whether an individual engages in predominately effectual or causal behaviour, with both Darwinians and Missionaries, who are described as goal-oriented, engaging in causal behaviour and Communitarians in effectual behaviour.

In drawing together the work by Fauchat and Gruber on entrepreneurial identity and Sarasvathy on effectuation and causation Alsos et al extend understanding both of the relationship between entrepreneurial identity and behaviour, and also of identity as an important antecedent of those two types of behaviour. In addition, this research builds on previous work that draws attention to the heterogeneity of entrepreneurs (Chell, 2008) which has important implications for the quality and type of advice given by business advisors and consultants as well as the development and costeffectiveness of appropriate policy.

Contemporaneous to the growing interest in an entrepreneur's identity scholars, also are seeking to understand the ways in which an organisation's identity can be developed and shaped: in other words, what are the consequences of asking the question "who are we as an organisation?". Snihur investigates this question by using the concept of optimal distinctiveness, the optimal balance between the need to be included in a group or category of similar actors and the need to be distinctive for ventures which have already established an organizational identity. She applies this to explore how entrepreneurs introducing innovations can make claims about uniqueness and category membership (legitimacy and reputation) for their ventures so they can both 'fit in' and 'stand out from' their competitors.

Adopting a social constructivist perspective Snihur is especially interested in extending understanding of the notion of a distinctive organisational identity (Albert and Whetten, 1985) through a case study methodology comprising four cases of business model innovators in different sectors (healthcare software, online grocery retailing, mobile applications and holiday rentals). The findings demonstrate that storytelling, use of analogies, procuring social evaluations and establishing alliances were the most commonly used devices to construct claims about organisational identity, with stories and analogies mainly employed by founders and the other two by both founders and employees.

This research extends that on organisational identity by demonstrating that it has a dual nature/ purpose reflecting dimensions of uniqueness and category membership, such as belonging to an accredited body or industrial sector and that it is important to achieve this simultaneously instead of focusing on establishing uniqueness only. Snihur also provides insights into organisational identity formation from both the individual-organisational and internal-external interface. In terms of a future research agenda she offers a set of propositions to explore fully the relationship between those entrepreneurial actions by different organisational actors taken to shape identity and at what stage they are deployed (timing).

Like Snuhur, Nelson et al draw attention to the tensions which organisations face between fitting in and remaining distinctive. Using an alternative organisational form, that of cooperatives, a group of firms united globally through shared values and practices, they present a conceptual paper to extend the literature on entrepreneurial organisational identity. Specifically, they consider those unconventional (from 
normative business practice) processes and procedures, which influence identity formation in this atypical setting. To develop a research agenda focused on organisational identity formation in cooperatives, they employ population ecology to theorise about the relationships between social expectations and institutional arrangements at the societal, population and organizational levels. Their starting point is that the ways in which cooperatives develop and express their identity as well as their strategic positioning is likely to be shaped by the cooperative organisation's distinctive global code. In particular, the focus on prioritising benefits to members, such as lower prices and a greater say in decision-making, instead of returns to shareholders provide different antecedents and values by which to underpin identity creation in a non-traditional organisational form.

Nelson et al argue that the adoption of a population ecology lens, which is informed by social constructionism, allows for a broader and more inclusive approach to identity formation. Population ecology encourages researchers to consider a nest set of influences at the macro, population and organizational level on identity formation. Accordingly, this includes key partners and other stakeholders instead of the unidirectional focus by entrepreneurship scholars on how founders and their founding teams develop their venture's identity and subsequently share it with an external audience. Like Snihur's research, this shifts the focus on organisational identity formation from an internal and uni-directional process to a bi-directional one that takes cognizance of the permeability of organizational boundaries and the influence of external relationships in how a firm can be positioned. This emphasis on a range of inter- and intra-organisational stakeholders underpins the propositions developed by Nelson et al which explore issues of alignment of business and economic values with those of cooperatives; the degree of embeddedness in cooperative networks; the mediating role of membership of cooperatives; and the degree of identity ambiguity experienced by an atypical organisational form.

\section{Conclusion}

This Special Issue has focused on identity, identity formation and identity work in entrepreneurship. In examining identity at various levels (e.g. individual, organisational) in different national and organizational contexts using a range of methodologies (primarily qualitative) and drawing on, for the most part, social constructionism, these papers meet our initial aspirations to consolidate existing embryonic theory development, stimulate new conceptual thinking and provide a framework for path-breaking empirical explorations of the topic. While these papers provide a valuable stimulus, there remain many fruitful avenues for future research. First, in terms of level, there is scope for more research on all units of analysis, including individual, team, the organization and the interorganisational, and the dynamic interrelationships among them, notably the relationship between and impact of founder identity and organisation identity and the nature of identity negotiation in the creation and/or functioning of entrepreneurial teams. Second, in terms of organizational context, there is a need for further studies of the process of identity formation in a wide range of entrepreneurial and SME contexts (size, stage of development, sector), identity and the family business (for example, the effect on family dynamics, conflict, succession planning, differences in identity between the founder and subsequent generation's identity, impact between family identity and non-family members), and in corporate entrepreneurship and the relationship between 
founder and professional manager/surrogate entrepreneur identities. Third, in terms of cultural context, research is needed on the relationship between identity and the expression of cultural understanding through images and symbolic capital in the entrepreneurial context as this varies within and across countries and regions. Fourth, in terms of focus, more research is needed on the nature and role of identity work in entrepreneurship, the processes by which identities are constructed and negotiated, identity formation and identity change in the entrepreneurial venture as a process over time, and on the paradox of entrepreneurial identity reflected in the tension between individual identity (implying dissimilarity/ heterogeneity) and identity as an entrepreneur (implying role-based similarity/ homogeneity). Finally, in terms of orientation, entrepreneurial identity research should move beyond the dominant emphasis on essentialist notions of identity-as-entity to more process-oriented view of identity-work-as-process, a temporally and contextually constrained domain of identity creation, representation, conflict and renewal that transcends the role/social and individual/organizational polarities that characterize much of the discourse to date. 


\section{References}

Ainsworth, S. and Hardy, C. (2004) Discourse and identities. In D. Grant, C. Hardy, C. Oswick and L. Putnam (eds) The Sage handbook of organizational discourse, London: Sage pp 153-173.

Albert, S. and Whetten, D. (1985) Organizational identity, in L. L. Cummings and B.M. Staw (eds) Research in Organizational Behaviour (vol 7) pp 263295.,Greenwich, CT: JAI Press.

Albert, S. Ashforth, B. E. and Dutton, J. E. (2000) Organizational identity and identification: Charting new waters and building new bridges, Academy of Management Review 25 (1) pp 13-17.

Alsos, G., Clausen, T., Hytti, U. and Solvoll, S. (forthcoming)ntrepreneurs' social identity and the preference of causal and effectual behaviours in start-up processes, Entrepreneurship and Regional Development

Alvesson, M. and Deetz, S. (2000) Doing Critical Management Research, London: Sage.

Anderson, A. R. and Warren, L. (2011) The entrepreneur as hero and jester: Enacting the entrepreneurial discourse, International Small Business Journal, 29 (6) pp 589-609.

Bauman, Z. (2000) Liquid Modernity, Cambridge: Polity Press

Berglund, K. (2006) Discursive diversity in fashioning entrepreneurial identity, in C. Steyaert and D. Hjorth (eds) Entrepreneurship as Social Change: A Third Movements in Entrepreneurship Book, Cheltenham, UK: Edward Elgar pp 231-250.

Binari, M. (2012) The emotional embeddedness of corporate entrepreneurship: The case of envy, Entrepreneurship Theory and Practice 36 (1) pp 141-170.

Boje, D. and Smith, R. (2010) Re-storying and visualising the changing entrepreneurial identities of Bill Gates and Richard Branson, Culture and Organization, 16, 307-331.

Carroll, B. and Levy, L. (2008) Defaulting to management: Leadership defined by what it is not, Organization 15 (1) pp 75-96.

Chell, E. (2008) The Entrepreneurial Personality: A Social Construction, London: Routledge.

Clegg, S. R. and Baumeler, C. (2010) Essai: From iron cages to liquid modernity in organizational analysis, Organization Change 31 (12) pp 1713-1733.

Cohen, L. and Musson, G. (2000) Entrepreneurial identities: Reflections from two case studies, Organization 7 (1) pp 31-48.

Côté, J. (1996). Sociological perspectives on identity formation: The culture-identity link and identity capital, Journal of Adolescence, 19, 417-428.

Coupland, C. and Brown, A. D. (2012) Identities in action: Processes and outcomes, Scandinavian Journal of Management 28 pp 1-4.

Davidsson, P. (2013) Some reflection on research 'schools' and geographies, Entrepreneurship and Regional Development 5 (1-2) pp 100-110.

Down, S. (2006) Narratives of enterprise: Crafting entrepreneurial identity in a small firm, Cheltenham, UK: Edward Elgar.

Down, S. and Reveley J. (2009) Between narration and interaction: Situating first-line supervisor identity work, Human Relations 62 (3), 379-401. 
Down, S. and Reveley, J. (2004) Generational Encounters and social formation of entrepreneurial identity: 'Young guns' and 'old farts', Organization 11 (2) pp 233-250.

Essers, C. and Benschop, Y. (2007) Enterprising identities: Female entrepreneurs of Moroccan or Turkish origin in the Netherlands, Organization Studies 28 (1) pp 49-69.

Fairhurst, G. (2009) - Considering context in discursive leadership research, Human Relations 62 (11) pp 1607-1634.

Falck, O., Heblich, S. and Ludemann, E. (2009) Identity and Entrepreneurship, CESIFO Working Paper No. 2661 (Category 4: Labour Markets - May 2009).

Fauchart, E. and Gruber, M. (2011) Darwinians, Communitarians and Missionaries: The Role of Founder Identity in Entrepreneurship, Academy of Management Journal, 54 (5), pp. 935 - 957.

Foss, L. (2004) 'Going against the grain'... Construction of entrepreneurial identity through narratives, in D. Hjorth and C. Steyaert (eds) Narrative and Discursive Approaches in Entrepreneurship: A Second Movements in Entrepreneurship Book, Cheltenham, UK: Edward Elgar, pp 80 -104.

Gartner, W. B. (2010) ENTER: Entrepreneurial narrative theory ethnomethdology and reflexivity, Clemson, South Carolina: Clemson University Digital Press

Gartner, W. B. (2013) Creating a community of difference in entrepreneurship scholarship, Entrepreneurship and Regional Development 25 (1-2) pp 5-15.

Germak, A. J., and Robinson, J. A. (2014). Exploring the motivation of nascent social entrepreneurs, Journal of Social Entrepreneurship, 5(1) pp 5-21.

Gioia, D. A., Patverdhan, S. D., Hamilton, A. L. and Corley, K. G. (2013) Organizational identity formation and change, Academy of Management Annals, 7 pp 123-193.

Gill, R., and Larson, G. S. (2014). Making the ideal (local) entrepreneur: Place and the regional development of high-tech entrepreneurial identity, Human Relations, 67(5) pp 519-542.

Harris, M. (1976) History and significance of the emic/etic distinction, Annual Review of Anthropology 5, 329-350.

Harrison, R. T. and Leitch, C. M. (1996) Discipline Emergence in entrepreneurship: Accumulative fragmentalism or paradigmatic science? Entrepreneurship, Innovation and Change 5 (2) pp 65-83.

Hatch, M. J. and Schultz, M. (2002) The dynamics of organsational identity, Human Relations, 55 pp 989-1018.

Haynie, M. J. and Shepherd, D. (2011) Toward a theory of discontinuous career transition: Investigating career transitions necessitated by traumatic life events, Journal of Applied Psychology 96 (3) pp 501-524.

Hoang, H. and Gimeno, J. (2010) Becoming a founder: How founder role identity affects entrepreneurial transitions and persistence in founding, Journal of Business Venturing 25 pp 41-53.

Hytti, U. (2005) New meanings for entrepreneurs: From risk-taking heroes to safeseeking professionals, Journal of Organizational Change Management, 18 (6) pp 594-611.

Johnson, P. and Duberley, J. (2000) Understanding Management Research, London: Sage.

Jones, C. and Spicer, A. (2009) Is the Marquis de Sade an entrepreneur? in D. Hjorth and C. Steyaert (eds) The Politics and Aesthetics of Entrepreneurship: A 
Fourth Movements in Entrepreneurship Book, Cheltenham, UK: Edward Elgar pp 131- 147.

Kenworthy, T. P. and McMullan, W. E. (2012) Importing Theory, paper presented to 2012 Babson College Entrepreneurship Research Conference, Texas, USA

Kjellander, B., Nordqvist, M. and Welter, F. (2012) Identity dynamics in the family business context: a novel('s) perspective, In A. L. Carsrud and M. Brännnback (eds) Understanding Family Businesses. International Studies in Entrepreneurship 15. Springer: New York, pp 39-53.

Krueger, N. (2007) What lies beneath? The experiential essence of entrepreneurial thinking, Entrepreneurship Theory and Practice January 31 (1) pp 123-138.

Laakkonen, A. (2012) Construction of the Entrepreneurial Identity in the Family Business Context: A Cross-Cultural Study, Jyväskylä University Printing House, Jyväskylä 2012 (http://dissertations.jyu.fi/studbusi/9789513945503.pdf - downloaded 5 March 2012)

Lewis, K. (forthcoming) Identity capital: An exploration in the context of youth social entrepreneurship, Entrepreneurship and Regional Development.

Lindgren, M. and Wåhlin, N. (2001) Identity construction among boundary crossing individuals, Scandinavian Journal of Management, 17 (3) pp 357-377.

Losee, R. M. (1995) The development and migration of concepts from donor to borrower disciplines: Sublanguage term use in hard and soft science, Proceedings of the Fifth International Conference on Scientometrics and Informetrics, Chicago, USA, pp 265-274.

Mabey, C. and Morrell, K. (2011) Editorial: Leadership in Crisis, Leadership, 7 (2): 107-119

Miller, D. and Le-Breton Miller, I. (2011) Governance, social identity and entrepreneurial orientation in closely held public companies, Entrepreneurship Theory and Practice, 35 (5) pp 1051-1076.

Morris MW, Leung K, Ames D and Lickel B (1999) views from inside and outside: integrating emic and etic insights about culture and justice judgement, Academy of Management Review 24, 781-796.

Murnieks, C. and Mosakowski, E. (2007) Who am I? Looking inside the 'Entrepreneurial Identity', Social Science Research Network (available at SSDRN: http:/ssrn.com/abstract=1064901).

Navis, C. and Glynn, M.A. (2011) Legitimate distinctiveness and the entrepreneurial identity: Influences on investor judgements of new venture plausibility, Academy of Management Review 36 (3) pp 479-499.

Nelson, T., Nelson, D., Huybrechts, B, Dufays, F., O’Shea, N. and Trasciani, G. (forthcoming) Emergent identity formation and the co-operative: Theory building in relation to alternative organizational forms, Entrepreneurship and Regional Development.

Obschonka, M. Maximilian, G., Silbereisen, R. K. And Cantor, U. (2012) Social identity and the transition to entrepreneurship: The role of group identification with workplace peers, Journal of Vocational Behaviour 80 pp 137-147.

Oliver, D. and Vough, H. C. (2012) Practicing identity: The emergence of organisational identity in start-up firms, paper presented at the 2012 Academy of Management Annual Meeting, Boston, USA.

Pohl, C. and Hirsch Hadron, G. (2008) Methodological challenges of transdisciplinary research, Natures Sciences Sociétés 16 (2) pp 111-121. 
Powell, E. E. and Baker, T. (2014) It's what you make of it: Founder identity and enacting strategic responses to adversity, Academy of Management Journal, 57(5) pp 1406-1433.

Reveley, J. and Down, S. (2009) Stigmatization and self-presentation in Australian entrepreneurial identity formation, in D. Hjorth and C. Steyaert (eds) The Politics and Aesthetics of Entrepreneurship: A Fourth Movements in Entrepreneurship Book, Cheltenham, UK: Edward Elgar pp 162-182.

Reynolds, P. (1991) Sociology and entrepreneurship: Concepts and contributions, Entrepreneurship Theory and Practice 16 (2) pp 47-70.

Sarasvathy, S. D. (2001) Causation and Effectuation: Toward a Theoretical Shift from Economic Inevitability to Entrepreneurial Contingency, The Academy of Management Review 26 (2) pp 243-63.

Sen, A. (2006) Identity and Violence: The Illusion of Destiny, New York: W. W. Norton.

Smith, I.H. and Woodworth, W. P. (2012) Developing social entrepreneurs and social innovators: A social identity and self-efficacy approach, Academy of Management Learning and Education 11 (3) pp 390-407.

Snihur, Y. (forthcoming) Developing optimal distinctiveness: organizational identity processes in new ventures engaged in business model innovation, Entrepreneurship and Regional Development.

Steyaert, C. (2007) 'Entrepreneuring' as a conceptual attractor? A review of process theories in 20 years of entrepreneurship studies, Entrepreneurship and Regional Development, 19 (6) pp 453-477.

Van Knippenberg, D., Van Knippenberg, B., De Cremer,D. and Hogg, M.A. (2004) Leadership, self and identity: A review and research agenda, The Leadership Quarterly 15 pp 825-856.

Watson, T. J. (2009) Entrepreneurial action identity work and the use of multiple discursive resources: The case of a rapidly changing family business, International Small Business Journal, 27 (3) pp 251-274.

Ybema, S., Keenoy, T., Oswick, C., Beverungen, A., Ellis, N. and Sabelis, I. (2009) Articulating identities, Human Relations, 62 (3) 299-322.

Yitshaki, R. and Kropp, F. (forthcoming) Entrepreneurial passions and identities in different contexts: A comparison between high-tech and social entrepreneurs, Entrepreneurship and Regional Development. 


\section{Figure 1: Social discourse, the origin of concepts and the mapping of entrepreneurial identity research exemplars}

\section{Relation to dominant social discourse}

Dissensus

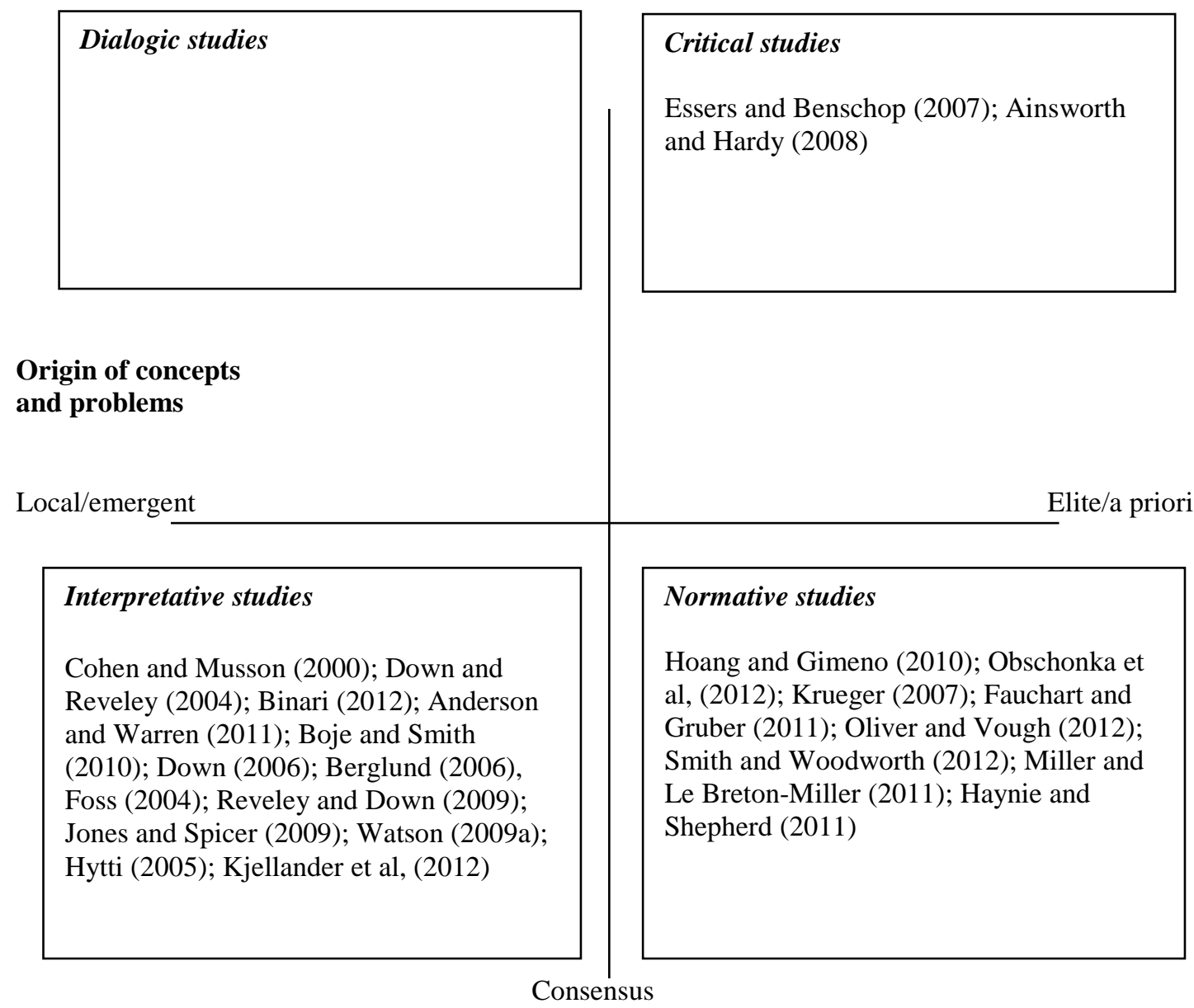

Source: Framework adapted from Alvesson and Deetz (2000) 